Accepted version, please cite as: Kattel, R., Lember, V. and Tõnurist, P. 2019. Collaborative Innovation and Human-Machine Networks. Public Management Review, forthcoming.

\title{
Collaborative Innovation and Human-Machine Networks
}

"HAL 9000: This mission is too important for me to allow you to jeopardize it."

2001: A Space Odyssey

Rainer Kattel

University College London, Institute for Innovation and Public Purpose, and Ragnar Nurkse Department of Innovation and Governance, Tallinn University of Technology;

r.kattel@ucl.ac.uk.

Veiko Lember

Ragnar Nurkse Department of Innovation and Governance, Tallinn University of Technology, and Public Governance Institute, KU Leuven; veiko.lember@kuleuven.be.

Piret Tõnurist

OECD, and Ragnar Nurkse Department of Innovation and Governance, Tallinn University of Technology; piret.tonurist@ttu.ee.

\section{Abstract}

As technology and automation are increasingly introduced to the public sector, the design of technology starts to influence how and with whom the public organizations collaborate. Machine-to-machine and human-to-machine interactions progressively delineate the space for innovation: who is involved, how they interact with each other, how the interactions are structured and what behaviors or actions emerge. The article asks: under which conditions does technology enhance or hinder collaboration? Through two exploratory case studies of transversal coordination and collaboration, this study shows that digital technology is not neutral, but it may act as a syntax of how public services evolve over time.

Keywords: digital government; collaborative innovation; network governance; humanmachine interaction; Estonia

Acknowledgements: The project leading to the paper has received funding from the European Union's Horizon 2020 research and innovation programme under the Marie SkłodowskaCurie grant agreement No 750378. 


\section{Introduction}

Growing digitization of the public service infrastructure leads to increasing computer-tocomputer or machine-to-machine $(\mathrm{m} 2 \mathrm{~m})$ traffic between public databases, often with the explicit aim of circumventing human agency (e.g., from motion-activated street lighting to automated renewal of licenses). In other words, coordination and collaboration in the public sector are increasingly dependent on automated routines. For instance, in Estonia, with a population of 1.3 million, there are around 44 million data inquiries per month made within its public digital infrastructure (so called $x$-road) and most of these inquiries are in fact automated $\mathrm{m} 2 \mathrm{~m}$ activities among databases owned and maintained by different public organizations. The key characteristic of computer-based automation is its dual nature: it replaces human activity and it generates information, it is reflexive (Zuboff 2015).

This paper seeks to understand whether and how such new $\mathrm{m} 2 \mathrm{~m}$ as well as human-tomachine $(\mathrm{h} 2 \mathrm{~m})$ patterns of coordination influence collaborative innovation practices in the public sector. Thus, we ask: how and under which conditions does the digitization of governance infrastructure enhance or hinder collaborative innovation? For this, we employ an analytical framework that focuses on the characteristics of human-to-machine networks and how they are inter-related with collaborative innovation processes. By digitization of governance infrastructure we mean processes in which $\mathrm{m} 2 \mathrm{~m}$ and $\mathrm{h} 2 \mathrm{~m}$ coordination and related governance structures such as digital platforms and data architecture are at the core of public sector and public services.

We discuss this issue based on two exploratory examples from Estonia, a global leader in digital government: first, the introduction of new value-added tax (VAT) filing rules and procedures that led to significant gains in VAT revenues; and second, the introduction of an e-residency program to offer Estonian public services globally (also called "country as a service"). More specifically, we apply a dynamic perspective and firstly look at the processes of collaborative networks leading to new technological solutions (VAT platform and eresidency) and how the existing digital infrastructure (e.g., automated and secure data exchange) shapes the evolution of the collaborative practices. Secondly, we analyze how digital innovations emerging from these collaborative networks (VAT platform and eresidency) further shape the developments in collaborative networks. In doing so, we do not 
focus on specific digital solutions applied for enhancing collaboration as such, but on how the digitization of infrastructure as a central environmental condition shapes the evolution of public-sector collaborative networks and, potentially, subsequent innovations.

Both empirical cases are examples of transversal coordination and collaboration that resulted from bottom-up initiatives, yet both cases assumed change in how citizens and private organizations participate in service delivery process. Most importantly, the cases show what human and machine interaction looks like in collaborative networks that lead to outcomes that are both synergetic between the two and deterministic to technological possibilities. While in the initiation phase both of the collaborative networks depended heavily on its charismatic leaders (human interactions), they were small in size and evolved through bottom-up coordination. During the implementation phase of the innovations, collaboration was transformed to a large extent into machine-to-machine interactions. We argue that, in both cases, the pre-existing digital infrastructure and $m 2 m$ coordination structures played a key role in these innovations both through enabling collaboration (the path from idea to implementation was made inexpensive by using existing $\mathrm{m} 2 \mathrm{~m}$ infrastructure) and through the automation of basic tasks (everyday overhead was made inexpensive by using existing $\mathrm{m} 2 \mathrm{~m}$ infrastructure).

However, we also show how the existing $\mathrm{m} 2 \mathrm{~m}$ infrastructure engenders new challenges for collaborative efforts. As Estonian central government is relatively decentralized, collaboration is framed and limited by possibilities of the digital infrastructure; anything beyond what the digital infrastructure enables is rather cumbersome and relies on charismatic leadership skills rather than on innovation and collaboration routines. In other words, innovation culture, digital service design and scale-up are shaped by and sometimes hindered by $\mathrm{m} 2 \mathrm{~m}$ infrastructure.

Therefore, where the centrality of $\mathrm{m} 2 \mathrm{~m}$ infrastructure increases - i.e., the stronger the digital 'syntax' - public sector collaborative innovations tend to gravitate more and more around what is technologically possible. In sum, we argue that as automation within public digital infrastructure tends to circumvent human agency, it also increasingly delineates space for collaboration, innovation and capacity, and hence the directionality of change in public sector. Thus, with increasing use of automation, machine learning and other 
emerging tools, public organizations need to emphasize processes of policy and social learning as well in order to make better use of digital opportunities (see also Stilgoe 2018). To make this argument, the article is structured as follows: first, we give a brief overview of collaborative innovation in the public sector; this is followed by a discussion of digital collaboration and the introduction of our analytical framework; third, we outline two exploratory Estonian cases with some contextual information; fourth, we discuss the cases and their wider importance for collaborative innovation.

\section{Collaborative innovation}

Why does collaboration matter for innovation? Simply put, innovation - and we will come back to what we mean by it below - is impossible without collaboration within a community of innovators (Nelson 2018). While open innovation and other similar concept have become popular over the last decade, Mowery and others have shown that already in late the $19^{\text {th }}$ century corporate R\&D was open and collaborative (Mowery 2009). For a public sector context, Hartley et al (2013) define collaboration as "the process through which two or more actors engage in a constructive management of differences in order to define common problems and develop joint solutions based on provisional agreements that may co-exist with disagreement and dissent." Opening up public sector organizations to external stakeholders (citizens, other governmental agencies, private and voluntary organizations) enables the public sector to take full advantage of the available external knowledge, and by creating interactive linkages between the internal and external stakeholders it can subsequently come up with novel solutions to public policy challenges (e.g., Bommert 2010). As we will see below, such openness to external actors can be particularly important in data and software areas that are intrinsically quite open and collaborative.

Rather than assuming or tasking the internal employees to come up with novel solutions or outsourcing the innovation processes altogether to the market or civil society, the advantage of collaborative innovation is expected to emerge from 'working together' with external partners (Huxham and Vangen 2004). Lowndes and Skelcher $(1998,315)$ - when analyzing inter-organizational partnerships - have argued that "the innovation has come in the form of strategies to develop interrelationships, trust and collaboration in an 
environment of resource scarcity where organizations would typically be oriented to defense and self-protection behind their bureaucratic ramparts."

And yet, while it is postulated that innovation often occurs in collaborative networks, innovative outcomes outside process-related practices (complex problem-solving and learning practices) are rarely studied in reality (Sorensen and Torfing, 2011). Thus, innovation in the public sector is mostly viewed through the processes and capabilities rather than through the results or outcomes themselves and the path-dependencies these create. Therefore, innovation in this article is understood through two layers: first, innovations bring detectable outcomes or value to actors involved (e.g., through simpler processes, lowered costs, new business opportunities, or similar); second, innovations can be related to new inter-and/or intra-organizational capabilities and routines (Nelson and Winter 1974; Kattel et al 2018; Lember et al 2018). In other words, innovations in the public sector emerge from and influence multi-actor settings and underlying routines. However, it is difficult to determine causality in this context. Collaboration as an explanatory variable is suspected to be highly endogenous: for example, it is difficult to delineate whether success in innovation (in joint solutions or processes) comes from collaboration itself or collaboration resulting from existing capabilities/routines that allowed the project to be successful (e.g., technology) (Dosi and Nelson, 2014; Gkypali, Filiou, and Tsekouras, 2017)This problem in research is usually abstracted away, but can be controlled for by conditioning the analysis on the decision to collaborate on factors that organizations cannot control. This puts the pressure on understanding how and why collaboration happens (so we can later analyze how technology influences these dynamics and maybe also how it affects the endogenous/exogenous nature of collaborative innovation).

\section{Collaborative innovation in the digital age}

Digital technologies have been at the center of the public sector collaborative innovation debates for some time now - yet somewhat separated thus far from the mainstream public administration discussions (see Dunleavy et al., 2006 and Pollitt 2012 for a general discussion). Some studies explore ICT as a crucial factor in creating optimal working conditions for collaborative innovations (Verhoest et al., 2017). Various e-government studies have focused on how inter-organizational collaboration shapes the enactment of digital technologies (e.g. Fountain 2001; Gil-Garcia et al., 2014). Crowdsourcing, digital co- 
production and other similar approaches are increasingly experimented with by governments to tap into the wisdom and input of the citizens (Noveck 2015; Lember et al. 2019). Relatedly, design thinking practices that place great value on engagement, collaboration and creativity, can be seen as part of a wider digital era governance culture (Kimbell 2011). As an overarching trend, political, social and market activities and interactions increasingly revolve around and are shaped by digital platforms that bring together different services, applications, technologies and people (Teece 2018; O’Reilly 2017; Janssen and Estevez 2013). Platforms, thus, have the capacity to reorganize how value is created, who captures the value and controls it (Kenney and Zyzman 2015).

What is usually not emphasized in the collaborative innovation literature is that, due to ubiquitous presence of the interconnected ICTs, it is not only the human-human interactions (as is done, e.g., in peer-to-peer governance literature where ICT enhances human interaction; Kostakis and Bauwens 2014) that we should concentrate on, but increasingly on human-to-machine $(\mathrm{h} 2 \mathrm{~m})$ and machine-to-machine $(\mathrm{m} 2 \mathrm{~m})$ interactions (Tsvetkova 2017). In other words, not just platforms are important factors for collaboration, but also automated data and information exchanges as forms of collaboration itself and as enablers of collaboration (Helfat and Raubitschek 2018). Indeed, we need to define a new form of collaboration: digital collaboration in which a key part is played by digital technology itself (either as a platform, digital-only solutions - services, analytics, dashboards, etc. - or as enabling infrastructure). More precisely, digital collaboration is a process in which software interacts independently with other digital and/or human agents. Thus, for instance, digital collaboration happens when judges or doctors use computer-generated guidelines for sentencing or for treatment decisions. This does not mean that the software has an agency similar to human agents, but that the humans who interact with digital technologies do not always understand or control the internal design logic of these technologies. Hence, the collaboration becomes dependent on data sources, how the data is entered into the platform, how it is digitally treated (algorithms that provide the analytics), what machine learning tasks are posed, and how the information is finally used (for a recent overview, see Kitchin et al., 2018). Digital collaboration does not simply add another layer into collaborative networks; we propose that collaboration in the digital context is a qualitatively different form of collaboration. 
The rapid developments in ICTs have increasingly allowed machines to carry out public sector tasks. It has given them both self-regulation agency to carry out these tasks independently and the ability to enable and determine human actions (Eide et al., 2016). Of course, technology as physical infrastructure has always played an important role in how public services are designed and delivered (Pollitt 2012). Digital technologies are qualitatively different insofar as they have the ability to act as the syntax of many public services: that is, digital technologies can potentially determine what the service is and how it functions (e.g., health services become personalized). Obviously, some services will be more strongly influenced by digital syntax (e.g., various licenses, social support payments) than others (e.g., public order and policing, physical infrastructure).

Thus, the rapidly increasing digitization, automation capabilities and platformization not only provide public sector with opportunities to increase efficiency and alleviate the socalled cost-disease problem (Baumol 1967), but it may potentially transform the ways government organizations create and capture public value, coordinate their tasks and activities, and how and why they collaborate (Brown et al., 2017). In other words, it can fundamentally affect how collaborative innovations happen and with what consequences. The increasing relevance of human-to-machine interactions makes us ask: what are the mechanisms through which digital syntax changes public services? Pollitt's (2012) discussion of how the interaction between public services and physical space changes how services are designed and delivered (e.g., physical location and distance of services play an important role in their delivery and consumption, and generate path-dependent policy cycles as physical infrastructures cannot be simply moved around), and indeed what they are in substance, opens up the possibility of viewing digital technology in a similar vein (Kattel and Karo 2016). However, as digital technology is in itself dynamic, best expressed through the use of artificial intelligence and machine learning, we can argue that digital technologies become not only part of the collaboration environment, but that their adaptive and dynamic nature is likely to impact collaboration itself (in substance and direction) more than physical infrastructure. Put simply: digital technology is not neutral. Consider, for example, either enforcing command and control structures in collaborative networks through codeenforced hierarchy or building in modularity for easier open access developments. Either option supports different types and forms of collaboration also for the benefit of 
innovation: either centrally controlled and steered or platform-based with less top-down managed interactions between actors. As technological solutions are especially prone to lock-in and strong feedback loops (Arthur 1989), the technological path-dependency becomes an important element in the evolution of collaborative innovations.

These emerging characteristics have been covered only sparingly in public administration literature. For instance, Emerson et al. (2012) argue that collaboration takes place in a collaborative governance regime - system context that delineates collaboration pathways -, yet their framework does not account for potential impact of technology on such regimes. In order to study these emerging characteristics, we utilize a framework proposed by Eide et al. (2016) and Tsvetkova et al. (2017), who distinguish between four analytical layers for analyzing human-to-machine networks: actors, interactions, networks, and behaviors. We complement this framework with insights from collaborative innovation and innovation capabilities literatures.

\section{Actors}

Eide et al. (2016) and Tsetkova et al. (2017) distinguish between human actors (ranging from individuals and organizational roles to organizations) and machine actors (ranging from single device to systems), which have distinctive capacities as to what they can (or are allowed to) do in the networks. Crucially, both capacities are interdependent on each other (ibid.). The differences between human and machine actors matter. In order for machines to be applicable to collaborative innovation, they need to be available, connected and secure. They do not exhibit traits (or agency) that are akin to people such as trust, reliance, altruism or irrationality, yet, they can show some degree of self-regulation (e.g. machine-learning algorithms). Currently, machines can solve very complex problems dependent on large datasets, but the subtleties of nuanced behavior are not well modeled. (Tsvetkova et al., 2017) Thus, digital technologies force the standardization of information and formalization of decision-making processes, which not only enables system-level processes and interorganizational linkages, but also lowers adaptability and the discretionary power of human actors (Bovis and Zouridis 2002).

Human agency in networks is further shaped by active management and leadership, where leaders need to be able act as conveners (bringing networks together), champions/sponsors 
(creating room for networks to act), mediators (facilitating networks) and catalysts (changing networks) (see also Mandell and Steelman 2011; Crosby et al., 2016). Collaborative networks have to be steered and managed in ways that influence their processes and outcomes without reverting too much to traditional forms of command and control, thus leaving room for collaborative innovation (Sørensen and Torfing 2016). These roles can be best implemented in supportive institutional context providing the network leaders centrality, legitimacy, access to resources and organizational back-up (ibid.).

One can notice an increasingly central role that digital leadership plays in the field. What has been less discussed in the existing literature is that digital collaboration often brings people into the public sector with rather specific skills and backgrounds to collaborations, namely ICT engineers and designers. That is, it is not only civil servants interacting with digital solutions but increasingly also a new 'class' of advisors and entrepreneurs-in-residence who have software engineering, digital design and similar backgrounds. More often than not, the most talented among this group come from private-sector ICT companies with start-up or agile cultures and mind-sets. (Mergel 2017) Thus, for instance, Estonia hired Taavi Kotka as government $\mathrm{ClO}$ in 2013 after he sold his shares in the successful ICT company Nortal and could not work for another private ICT company for several years due to a non-compete clause. Similarly, Italy's Team Digitale was founded in 2016 and was initially led (until the end of 2018) by former Amazon.com top executive Diego Piacentini. The UK's Government Digital Service was co-founded by Mike Bracken, who had previously worked for the Guardian and other private companies. These digital leaders brought with them tens and hundreds of engineers, designers and others from private sector, academe and non-profits.

ICT-driven agile culture brings important new capabilities to public sector, e.g., reliance on open source software, disruption as a business model, a user-centric approach to service development and data-driven analytics that do not necessarily fit well with typical public sector organizations and evaluation practices. Such practices also transcend organizational boundaries and create networks based on specific technological knowledge that are driven by common values and held together by (digital) charismatic leadership. For instance, one of the strategic goals of Italy's Team Digitale is to create a community of developers - called 
Developers Italia ${ }^{1}$ - spanning private companies, non-profits and digital officers in various public administrations both in central and local governments. Similarly, in the Estonian startup community, there are a number of companies associated with former Skype employees who have loosely organized themselves under the moniker of "skype mafia" to denote a community of developers and entrepreneurs with shared values and ideas. ${ }^{2}$

Thus, we can expect the actors and their agency to be different in human-to-human, human-to-machine and machine-to-machine collaborations as the increasing dependence on digital skills, digital leadership, digital culture and machines with increasing selfcorrecting agency shapes the direction of the innovation journeys.

\section{Interactions}

The way the different human and machine agencies play out in collaborative innovation contexts depend on how their interactions evolve. In human-to-machine interactions, one can delineate among three types: human-to-human interactions, human-to-machine interactions, and machine-to-machine interactions (Eide et al., 2016; Tsvetkova et al., 2017). The types of human-to-human interactions define and are defined by the level of trust, familiarity, social heterogeneity and access to complementary skills and knowledge, while the human-to-machine and machine-to-machine interactions can be described through the nature and strength of those interactions (ibid.).

We know from previous studies that the nature and quality of interactions in terms of synergy, commitment-building and transformational learning are the key drivers of collaborative innovation (Sorensen and Torfing, 2011; Hartley et al., 2013). As such, the following contextual factors can influence the inter-organizational innovation processes: (1) history of relationships (lack of, negative or positive); (2) relative power of members; (3) imposition of rules/guidelines (interplay between and influence of formal and informal rules); (4) impact of political/cultural context (supportive or hostile); (5) type of issue (highly controversial or non-controversial); and (6) culture of members (value systems, norms, attitudes and beliefs) (Mandell and Steelman 2011). Thus, the innovation-related complications may include negative past experiences, a lack of motivation among

\footnotetext{
${ }^{1}$ See for details: https://developers.italia.it/en.

${ }^{2}$ See for details: http://skypemafia.com.
} 
stakeholders, too large a conflict of interests that prevents collaboration, the prevalence of mistrust and opportunistic behavior, the presence of procedural uncertainty and the existence of incompatible cognitive and discursive frameworks, closed networks fostering groupthink, strategic uncertainty, incomplete institutionalization of network arenas and communication failures (Hartley et al., 2013). As such, one can identify relational, 'collaboration capabilities' which rely on actors' capabilities to build and manage network relationships based on mutual trust, communication and commitment (Blomqvist and Levy 2006).

As indicated above, machines do not exhibit traits that are akin to people. Yet the role given to machines depends on the digital capabilities of the organizations and individuals involved. Machines have thus far been seen as 'mediators' of knowledge flows connecting people to people or allowing people to interact with various (aggregate or even algorithmically generated or customized) contributions. However, the more control machines start to exercise over the content they show by personalizing or customizing formation, the more they should be analyzed as distinct partners in $\mathrm{h} 2 \mathrm{~m}$ and even $\mathrm{m} 2 \mathrm{~m}$ interactions. This emerging role of digital elements - from data to culture - does not translate easily into a public-sector context where silos or coordination difficulties between ministries and departments are rather normal, and where political and legal frameworks prevent rapid changes, and where results are notoriously difficult to measure (Mintzberg 1996; Kattel et al 2018). This mismatch is an increasingly central source of conflicts in public sector innovation networks that, depending on a circumstance, may or may not lead to productive interactions, learning and novel solutions.

\section{Networks}

Digitalization for some time has been looked through the lens of actor-network theory (Callon, 1987; Latour, 2005) where digitization is seen as an 'actor' itself influencing and modifying social relationships. Originally quite radical in sociology, it proposed that not only humans were part of the social world, but that human agents as well as machines are effects of diverse networks of materials. Thus, the theory has been mostly concerned with how these (stable) networks of aligned interests emerge (Shaw-Garlock, 2010). Yet, in many cases technology is seen as a 'contextual actor' that participates in the system, but only has the role of shaping the system, not having any inertia or agency themselves (Sayes, 2014; 
Schmitz Weiss and Domingo, 2010). This in some ways is already changing. Thus, the theory has been critiqued for being too narrow and restrictive in scope to describe $h 2 \mathrm{~m}$ interactions.

There are, however, some researchers that go further: here we are interested in networks in which human and machine interactions have synergistic effects (Tsetkova et al., 2017). These are situations in which humans by themselves are not able to produce the effects envisioned, but in which the role of machines goes beyond simply being intermediary technologies as they transform and/or influence networks (ibid.). The network layer is about "the integration of actors and interaction into larger compounds and aims toward defining types of such sets of actors and interactions" (Eide et al., 2016). Here the network growth in terms of size and spread are considered key (ibid.). In essence, we can describe and understand here the kind of innovation collaboration networks that emerge in the context of public sector.

We can expect different types of collaborative innovation networks to arise, depending on the specific characteristics of the human-to-machine actors and interactions. Yet, in general, we can assume that collaboration is a viable option only if knowledge (technology) can be created and transferred between various groups more effectively by involving external partners and if the transaction costs to innovate with partners are low enough in comparison to the outcomes (Kogut and Zander 1992). So the viability and growth of collaborative innovation are dependent on technology and time (Baldwin and von Hippel 2011). In other words, technology itself shapes directly what kind of networks arise and how they evolve.

\section{Behaviors}

Digital collaborations as a form of human-to-machine networks provoke the emergence of new qualities such as the characteristics and roles of humans, organizations and machines, new patterns of interaction in the network, new applications of the network, and the overall evolution of the network (Eide 2016). Therefore, through change in behaviors we can evaluate the effect of digital technologies on collaborative innovation processes and outcomes. This analytical layer concerns predominantly the networks' capacity to change how different actors are inter-related through workflows and how they coordinate 
(synchronize) their activities, and whether a network evolves through top-down controlled organization or in a bottom-up self-organized manner (ibid.).

Digitization, automation and platformization fundamentally challenge how collaborative networks are to be coordinated. One the one hand, $\mathrm{h} 2 \mathrm{~m}$ and especially $\mathrm{m} 2 \mathrm{~m}$ coordination is based on a mix of traditional coordination elements (for the latter, see Bouckaert et al., 2010). It is strongly hierarchical as code-based decision-making rules usually leave little choice for the stakeholders involved to bargain or negotiate about or even ignore the codeimposed rules. This tendency is especially central should the network be organized topdown. It also has strong elements of network-type coordination, especially if the organizations involved favor bottom-up experimentation (Tõnurist et al 2017) or if the $\mathrm{m} 2 \mathrm{~m}$ infrastructure is co-created with external organizations and they have the choice to decide whether and how to join and to develop joint IT processes and platforms. This coordination approach naturally benefits if based on bottom-up organizational forms. Also, $\mathrm{m} 2 \mathrm{~m}$ coordination can be used to facilitate bargaining and competition within and among different public service providers (e.g. consider government as a platform such as Google Play or the Apple App Store). This approach is usually a mix of top-down and bottom-up modes of organization. On the other hand, $\mathrm{m} 2 \mathrm{~m}$ coordination has emerged with distinctively new elements. It has the ability to automatically align organizational behavior across the board and without active human interactions (scale effect), it can reduce the need for human interaction to zero (near zero marginal cost effect) and seemingly squeeze out contextual and value-based judgment in public service delivery (transforming inherently explicit political issues into implicit). Also, it places utmost importance on technological capacities as a main coordination resource that becomes the key source of network authority and that can fundamentally discriminate against certain stakeholders' groups or neglect important activities (e.g. passive inclusion of citizens' digital traces vs. active engagement of citizens, Lember et al. 2019). With the increasing use of artificial intelligence and machine learning in $\mathrm{m} 2 \mathrm{~m}$ interactions, such coordination practices have the potential to become policy-independent. ${ }^{3}$ Also, we can expect that the specific ICT capabilities that the

\footnotetext{
${ }^{3}$ See, however, discussion of racial and other biases in software used by some US courts, (Propublica 2016) and other public organizations (O'Neil 2016).
} 
new 'class' of tech-savvy public servants brings to public-sector collaborative innovation networks will become a key source of authority in these networks.

Thus, based on the adapted analytical framework of Eide (2016) and Tsvetkova et al. (2017), we can assume that in a collaborative innovation setting, technology has the potential to influence the operationalization of the different component that feed into collaborative innovation: who and what capabilities are involved in collaborative innovation (actors); what and how interactions in collaborative innovation settings happen (interactions); how these components are structured (networks); and which actions are taken and which types of innovations are proposed in the first place (behaviors).

\section{Background of the cases and methodological approach}

Estonia has internationally a strong e-state profile (Kalvet 2012; Margetts and Naumann 2017; Drechsler 2018). Famous for its e-government developments, particularly the electronic ID card and secure data exchange architecture (so-called X-Road) underlying it, Estonia has successfully launched one of the leading solutions of its kind globally. Near universal diffusion of the electronic ID card among the citizens has led to the fact that almost all personal income taxes are filed online, nearly all medical prescriptions are issued electronically, and other e-services cover a wide range of areas (central and local governments offer some $2500+$ services fully on-line). The country has also been trying to take the lead in the field of cybersecurity (Crandall and Allan 2015) and proposed to partner up with Uber to use the Estonian e-government infrastructure to fully automate the tax declaration process for Uber drivers globally. At the same time, Estonia is known for its exceptionally high social trust towards e-government solutions, where privacy-related issues have very little impact on policy debates and where ICT has become one of the building blocks of national branding. (Lember et al., 2018)

Our study does not aim to be representative, but is exploratory in nature as there are very few studies around focusing on digitization and collaborative innovations in the public sector. To extend the theoretical underpinnings of collaborative innovation, we focus on two of the most striking cases from recent developments in digital government in Estonia: the e-residency program that offers electronic residency globally and the reform of how 
value-added tax (VAT) payments are filed (all payments of over 1000 euros have to be filed electronically). Both cases targeted a specific policy problem, have achieved quite spectacular direct and indirect results/outcomes, have relied heavily on collaboration with various strands of government and would be impossible without the existing digital infrastructure. Based on our prior work (Lember et al., 2018), both empirical examples were most often cited as recent success cases in Estonian e-governance. The study is based on 32 semi-structured interviews with 29 people directly involved in either of the innovations or who are important actors in Estonian e-government. The key e-governance people and decision-makers were first identified from desk research based on document analysis that involved background data-gathering from various sources such as research articles, media, policy papers and government reports. In addition, we relied on a 'snowballing method' by which interviewed persons pointed us toward other key people. We also relied on the knowledge gained from our previous studies of Estonian digital government (ibid.). The interviews were carried out from March 2016 to June 2017(with follow-up interviews in April 2019) and covered historical accounts of the innovation processes under review (the actors who were involved in initiating and implementing the projects, the types of interactions that people had before and after the innovations were implemented, new forms of collaboration and networks that emerged and how organizational routines and peoples' behaviors shifted through the innovations).

\section{E-residency}

E-residency as an idea - that non-resident of Estonia can apply for essentially a limited residency that allows the use of digital public services such as establishing a company, filing taxes, etc., without physically being in Estonia - grew out of a practical need (interviewed policy-makers). Estonia has been using digital signatures for 15 years and, as the digital signature is based on e-ID card issued to residents and citizens, it is a mandatory form of identification, based on a unique ID number. However, foreign residents owning companies in Estonia or working on oversight boards of Estonian companies - Estonia has been one of the largest recipients of foreign direct investments in Central and Eastern Europe - faced a sudden problem: they had to sign documents physically, which created problems in terms of time loss and duplications of documents (residents signing digitally, non-residents physically). This affected around 50,000 non-residents and thus the idea was to offer them a 
version of the residency that is tied to digital services. At the same time, Estonia faces demographic decline through population aging, low birth rates and emigration. This added potency to the idea of e-residency: perhaps Estonia can overcome population challenge via digital residents who will eventually not only use digital services, but also increasingly pay taxes in Estonia that would offset service costs. Thus, the idea to service 50,000 nonresident businessmen arose from the idea of 10 million e-Estonians.

\section{Actors}

According to the interviewees, the key organizational actors involved were: the Ministry of Economic Affairs and Communication together with its agency Enterprise Estonia as coordinating and initiating agent; the Ministry of Interior, in charge of issuing e-ID cards and respective background checks and collaboration with other countries; the Ministry of Justice for adjusting the legal framework; the Ministry of Finance for changing the way bank accounts can be opened in Estonia and adjusting money laundering regulations; and the Ministry of Foreign Affairs for collaborations with other countries and promoting the idea globally. While the first ideas around this issue emerged in 2008 , the gestation and realization of the idea accelerated with Taavi Kotka becoming government chief innovation officer (CIO) (2013-2017) and Siim Sikkut becoming ICT advisor to the prime minister (and following Kotka as $\mathrm{CIO}$ in 2017). They had a highly eager counterpart in Ruth Annus in the Ministry of Interior Affairs. It took less than a year to create a small team, manned with people with start-up experience, with shoestring budget and located at arms-length within Enterprise Estonia.

Thus, the strong leadership and the ability to bring various partners on board in creating the service network was central to its initial success. Yet, the overall functioning of the eresidency platform was coordinated by the machine-to-machine solutions, based on the $x$ road, and cutting out human agency. The program relies on existing $x$-road infrastructure that connects decentralized databases and enables $\mathrm{m} 2 \mathrm{~m}$ traffic. Indeed, the relatively low costs of the program are possible because much of coordination behind the service is automatic. In substance, the program has a public access point for applicants and a dashboard to follow its development (http://e-resident.gov.ee and https://app.cyfe.com/dashboards/195223/5587fe4e52036102283711615553 respectively). Importantly, the network neither launched nor developed new digital infrastructure for the 
e-residency. Instead, its options and solutions relied - and indeed were determined by - the available digital infrastructure that enabled secure connectivity between the databases and devices involved.

\section{Interactions}

In the initiation phase, the capabilities, values, attitudes, norms, interests and knowledge clearly differed among the stakeholders. This divergence revolved around the IT business and start-up culture vs. the traditional public-sector culture oriented toward stability, but was eventually resolved through large-scale cross-ministerial collaboration (interviewed stakeholders). The power asymmetry among the various stakeholders in both cases was manageable, meaning that the stakeholders could overcome this because they had highlevel backing and relatively low costs associated. Initially, many key stakeholders were reluctant to collaborate and trust was lacking. It took years for the idea to mature and the break in the deadlock was marked an op-ed by the governments' $\mathrm{ClO}$ which gained a lot of positive public attention while providing the decision-makers extra legitimacy (to develop further the global e-Estonia narrative) for follow-up concrete actions. After this breaking point the program was able to secure also financial resources where the government $\mathrm{ClO}^{\prime} \mathrm{s}$ role was again instrumental. This enabled the network to be formed, core team to be hired and a rapid learning process to begin, all of which culminated in a rather clear network with strong ties.

As was indicated, budgeting issues were not paramount as technically the initiative was not very expensive (in addition, the investments came from EU structural funds rather than from the government's own sources). Still, for some stakeholders (e.g. police) the eresidency case added costs to carrying out the background control function, while some other costs were transferred to external parties (e.g. background checking for money laundering for banks).

At the macro-level, the highly supportive attitudes of political elite and society in general towards the idea of digital government provided an additional source of legitimacy to find common ground within the collaborative networks and provided the network leaders the centrality, legitimacy, access to resources and organizational back-up to fulfill their roles. 
Crucially, the role of machine interactions was key in the whole process as the implementation of the very idea of e-residency was determined by what the underlying technologies (e.g. x-road) enabled. Yet, the technology itself is already setting boundaries to collaborations for the e-Residency team - especially when developing further services for eresidents based on the technological platform. Thus, the interactions with the broader partners (police, tax and customs etc.) during the implementation phase of the program also had to follow the $x$-road solutions structuring the types of interactions and data exchanges between public organizations that were possible. Consequently, collaboration is easier with public organizations and private companies that have subscribed and use Estonian e-identity systems.

\section{Networks}

Although the number of organizations involved was not big at the conceptualization of the program, a rather complex network emerged with stakeholders involved from public finance, interior, economic development, public service modernization and private banks. At the infrastructural level, the collaboration relied on existing technologies (x-road as the backbone of the collaboration), and new interactions and networks were formed on the service level (from application processes to new services and progress dashboard). Importantly, the $\mathrm{m} 2 \mathrm{~m}$ interactions enabled radical and quick expansion of the geographical reach of the network as it became globally accessible right from the start of the implementation phase. However, the technology also presupposed a gatekeeper for the human-to-machine interaction: all participants had to have an e-ID (id-card) from the state to enter the x-road in a secure manner. Thus, this network eventually evolved towards becoming a synergistic human-machine collaboration where the innovation would not have been realized unless the human network and digital network were coordinated simultaneously.

It is significant that the collaborative innovation case took place among government departments and agencies with people with private sector and start-up backgrounds playing key galvanizing and accelerator roles. The private sector has had an important role in Estonia's e-government infrastructure evolution (from banks and telecoms in the 1990s to Skype and its explosion of talent and venture funding in 2000s) but it can be argued that, in essence, the sectors exist largely in parallel. Private ICT successes are achieved in the 
international arena since the domestic market is tiny (e.g. Transferwise and others); efforts to export public sector e-government solutions are there but have not been as numerous as was initially hoped. Yet, existing and well-functioning digital infrastructure, $x$-road as connecting layer between decentralized databases, e-ID for identification, played a crucial role, as their high acceptance, transparency and reliability enabled effective collaboration and rapid implementation in both cases. Thus, e-residency can be also seen as a novel way to accommodate the pressure from challenges experienced in exporting e-government solutions by digitally linking foreign residents and businesses with various domestic services.

\section{Behaviors}

Internal reorganization was needed for some collaborating organizations, which, according to the interviewees, prolonged the process quite a bit (e.g. background check by police, opening bank accounts). However, as the planned activities and outputs were highly standardized and relied heavily on the existing digital infrastructure, the standardization of processes and goals was technically rather straightforward.

Radically new behavior in the public sector context emerged in the way the core team under Enterprise Estonia implemented the program. The E-residency program was essentially an attempt to create a new digital platform with a global reach. Yet, in order to enable the prospective e-residents to join the network, the E-residency team had to overcome the limitations that the underlying digital infrastructure (x-road) had. There was the need to develop new digital services to bring prospective e-residents to the platform, but as the $x$ road infrastructure cannot be opened up to foreign service providers with no Estonian electronic ID, it was up to the E-residency team to act as a government start-up and to provide the needed services. In other words, although the existing digital infrastructure made it relatively cheap to automate the interactions between the network stakeholders, it also determined the role and actions the lead stakeholders had to take.

Thus, the program team conceives of itself as a start-up organization within government, and was initially housed physically among other start-ups (in fact within the same building with Transferwise's - a global fintech company - Estonian office). Data-driven analytics are deployed to determine and evolve use cases of potential customers with advertising campaigns following. The program is run on a payroll budget of approximately 300,000 euro, plus 4 million euro of investment funding from EU structural funds. 
Although the implementation of e-residency required relatively few legal changes, a central change involved a switch to digital opening of a bank account. This aspect met the most resistance (especially from Ministry of Finance) and assumed changes in stakeholders' behavior. However, the key innovation lies, in fact, in the idea of identity itself: physical identification equals e-identification for both Estonians and non-Estonians. This could be done only because of the existing digital infrastructure, its security and cultural acceptance in Estonia and beyond.

While the aftershocks of recent money-laundering scandals in the domestic banking sector have created several challenges for the program, it can so far be seen as a spectacular success: on the one hand, there are now over 4,200 companies established by its 27,000 eresidents from more than 140 different countries (by November 2017), which represents an increase of ca. 3\% in Estonia's working age population; on the hand other, the program has further cemented Estonia's image and brand internationally as a globally leading digital country. Moreover, as the latest study claimed, the program has generated 14.4 M EUR of direct and indirect income for the government.

The program has led to further new initiatives and experimentations such as opening eResidency centers in foreign countries (first opened in Seoul in 2017), the proposal to offer crypto tokens (initial coin offering) and it has been part of the narrative for developing the first-ever attempt to legalize artificial intelligence. Also, the e-Residency program is a founding partner of the UNCTAD's new initiative to ensure access to e-commerce for more entrepreneurs in the developing world (e-Trade For All).

\section{VAT declaration}

The VAT declaration case arose from the realization that VAT fraud was rampant in Estonia and that the fraud cases had not diminished for over a decade despite various efforts. At the same time, almost all physical persons' tax filings were done electronically, evidence that the digital infrastructure for the tax system had reached universal acceptability. In 2014, it became compulsory for companies to declare transactions over $1000 \mathrm{EUR}$. The reform relies on existing e-government infrastructure (again, x-road data exchange, data gathering) and its high acceptance among the public. While there were claims of increased administrative burden to companies, the Tax Board provided a machine-to-machine solution to firms to declare the invoices directly from their accounting software. 


\section{Actors}

Already in 2005, the Tax and Customs Board suggested a digital reform of VAT filing to the Ministry of Finance, but the idea failed to gain traction. In 2014, the deputy head of Tax and Customs Board Egon Veermäe again suggested the reform to the Ministry, and this time the idea was taken up. In essence, this reform was a close collaboration between the Tax and Customs Board, the Ministry of Finance, the Ministry of Economic Affairs and Communications and accounting software providers. The reform required ca. 500,000 euros of new ICT investment (done in the Tax and Customs Board; secured by Kotka), but it faced a huge backlash from various industry associations and the media in general. Jürgen Ligi's support, the Minister of Finance at the time, proved crucial in the face of heavy critique in Parliament and the media, as were Kotka's and Marek Helm's (head of the Tax and Customs Board) appearances in news media. As in the e-residency case, the government ClO Kotka acted both as a motivator and as a galvanizer of innovations, and in this case his background as software engineer and successful ICT businessman gave him legitimacy and a voice to argue that, in terms of digital aspects, the reform was not a complex issue.

So it was again the role of the key leaders in the process who absorbed the risks and enabled the network to be initiated. During the implementation phase, the interaction between actors was, however, fully automated.

\section{Interactions}

Similarly to the e-residency case, there was very strong political and administrative resistance to the initiatives in the beginning, yet this changed drastically during the early debates, as the initiative promised to bring direct income to the state budget during a time of very slow economic growth. As was the case with the e-residency program, it was the authority of the leading figures of the network that made it possible to resolve the conflicts within and beyond the network, build legitimacy for the network, whereas this authority was largely based on the personal digital competences of the leaders of the network themselves and also organizationally (Tax and Customs Board had a reputation as a highly capable digital organization). That is, technical capabilities were very much the basis of authority in the network. 
The learning process was made relatively cheap because of $m 2 m$ solutions and existing einfrastructure, meaning that a lack of resources was not among the inhibiting factors. Moreover, some other costs were transferred to external parties (e.g. technical upgrading of accounting software for companies and other public and private organizations). The

austerity context added somewhat to the performance pressure. As the VAT filing is a very standardized service, the impact of innovation was also very easy to measure (dynamics in VAT levied became visible in a month time), making the feedback loops very rapid. The same holds for the case of e-residency as change was easy to understand for all stakeholders in terms of number of new e-residents, new companies registered and taxes paid. Hence, as results were easy to measure, this enabled the performance pressure to act as a key driver in both processes.

\section{Networks}

Organizationally speaking, the formed network was relatively less complex compared to the e-residency case. In addition to the fiscal and economic policy-making fields, business associations and accounting software companies were the core members of the network. While the existing Estonian public sector e-infrastructure provided the basis for the collaborative innovation, the successful implementation of the initiative assumed the formation of a new automated $\mathrm{m} 2 \mathrm{~m}$ layer between the Tax Board and thousands of business organizations affected by the new VAT filing system. Similarly to the e-residency case, the inherent feature of the formed $\mathrm{h} 2 \mathrm{~m}$ network was its capacity to connect VAT subjects in real time and across the country. That is, the geographical extension was wide and quickly achieved thanks to the established h2m network. The network massively expanded during the implementation phase, but organizations were involved through technological means requiring little or no human involvement in the networks themselves. When analyzing the critical conditions enabling the process and outcomes of the VAT declaration case, we can see how the interconnectedness of individual, organizational and network governance factors shaped the outcomes (in fact, the same holds for the eresidency case as well). The learning process and implementation of both initiatives was enabled by strong leadership in both cases. Charismatic leaders were in leading positions in both networks. Risk-taking was very much tolerated by the network leaders who were strongly gambling with their personal reputations; key persons had a business-like attitude 
to the public sector and were very much driven by performance pressures. The collaboration took place among government departments and agencies with people with private sector and start-up backgrounds playing key galvanizing and accelerator roles.

\section{Behaviors}

The reform turned out be a huge success. In the first year, VAT revenue increased by $12 \%$ (195 million euros) and this new level has proven sustainable in subsequent years.

Moreover, the declaration reform has given the Tax and Customs Board enormous real-time data on the Estonian economy as transactions exceeding 1000 euro represent ca. $2 / 3$ of all transactions. This has led the Ministry of Economic Affairs and the Tax and Customs Board to seek further innovations through big data analytics based on VAT filings: experiments to predict economic behavior in various sectors and regions are underway. These developments truly predict the advance of $\mathrm{h} 2 \mathrm{~m}$ or $\mathrm{m} 2 \mathrm{~m}$ collaboration, where digital syntax will presuppose the tax cases the Board will deal with. By implementing this test case, the Tax and Customs Board knows that behaviorally private companies are de facto ready for broader roll-out of machine-to-machine coordinated solutions. Companies had to upgrade their technological capabilities and thus, the Board can now implement similar solutions much more quickly. The organization is moving towards a more targeted approach in terms of addressing tax fraud and avoidance, and is also developing new services based on the information that the algorithms are able to predict (difficulties of firms etc.). This shows that learning and activities - and hence further innovative solutions - will start to depend on information that the technology will produce.

\section{Discussion and conclusion}

The two cases are examples of collaborative innovation. That is, a significant change in government practices is achieved only because of inter-organizational collaboration. No partner could have achieved this without the presence and input from others. Working together clearly was foundational. Clear networks were formed around specific policy issues (business environment; tax evasion) where the involved stakeholders all bore costs and risks, brought specific knowledge and resources. These were more or less self-organized networks (joint activities between agencies from different ministries; in Estonian tradition 
ministries/policy fields are highly independent with almost no central horizontal policymaking capacity even at the level of prime minister). These were also collaborative innovation cases that were not only strongly shaped by the existing digital infrastructure and capacities, but that would not have been possible without the use of digital technologies, and this also led to new digital solutions and further collaborative initiatives. Therefore, how and under which conditions does the digitization of governance infrastructure enhance or hinder collaborative innovation? As both collaborative innovation cases relied fundamentally on $\mathrm{m} 2 \mathrm{~m}$ coordination and other ICT capabilities, this demonstrates how digital capabilities have become the core capabilities not only in bringing networks together and governing networks, but in public sector in general. Both cases have been highly successful in their primary goals and have opened up significant new avenues for innovations because of their high digital content. While both innovations led to direct outcomes (ease of doing business for 50,000 foreign company owners/managers, $12 \%$ increase in VAT revenue, respectively) both collaborations initiated entirely new areas of public activity. The E-residency program created the field of public service export and VAT declarations created the field of predictive analytics in fiscal, economic and regional policy. That is, the success of these digital solutions increasingly led to new similar initiatives, gradually increasing the centrality of human-machine coordination and networks.

Overall, what both cases demonstrate is that due to the advancements in ICT, the public sector is clearly moving away from purely human-to-human (h2h) interactions and networks toward human-machine ( $\mathrm{h} 2 \mathrm{~m})$ networks. That is, we increasingly witness a gradual move toward collaborative innovation practices whose effectiveness relies on the synergistic interactions between humans and machines. To follow Eide et al. (2016) and Tsetkova et al. (2017), we can suggest that in both cases we saw the emergence of digital collaboration networks, which:

a) Redefine the roles of humans, organizations and machines as actors in collaborative processes as the centrality of digital technologies increasingly determine how networks can design, implement and evaluate public policies, i.e. who interacts with each other and how. As automated, $\mathrm{m} 2 \mathrm{~m}$, service delivery was ultimately the main modus operandi both networks aimed at, the existing digital infrastructure determined also what the networks were able to plan and execute. In both cases, 
the digital infrastructure underlies organizational routines and capacities, and extends them through collaboration to new services.

b) Create new patterns of interactions in networks as authority and power become a function of digital skills and business thinking, and as the implementation and decision-making tasks are increasingly delegated to machines. Digital charismatic leadership provided by an influx of ICT leaders who understand what technologically, human-to-machine, is possible, and who legitimize the new emerging humanmachine collaborations and related organizational routines and capacities. Furthermore, the interactions increase exponentially in the implementation phases of the collaborative projects, but these interactions start to rely more on machineto-machine coordination.

c) Lead to new applications in the network as both initiatives were possible only because of digital technologies and qualify as global (e-residency) and domestic (VAT) innovations, while paving ways to new innovations (e.g. new types of access to government services or predictive policy-making though the creation of new sources of digital paths);

d) Create new evolution patterns and behaviors within networks as $\mathrm{m} 2 \mathrm{~m}$ coordination gradually becomes the central coordination mode while triggering the development and institutionalization of new (digital) capacities in partner organizations that lead to further evolution in collaborative innovation practices.

Moreover, the digital infrastructure and capacities underlying both cases clearly enhanced the process and outcomes of the collaborative innovation initiatives. Without the high-level technological capacities of key members and the centrality of digital infrastructure, the collaboration could not become reality. However, based on the new evolutionary patterns emerging from the studied collaborative networks, we can see that the combination of the existing digital infrastructure, technological capacities and perceived performance success also strongly shape the choices about and focus of the emerging collaborative innovation paths.

As the overall context of the case studies was rather unique (both the smallness of the country as well as its underlying digital infrastructure play a role), the lessons learned can be generalized only to a limited extent in the specific cases per se. However, we think that the 
cases demonstrate well the types of new dynamics that emerge from collaborative innovation processes when they move away from purely human-to-human interactions towards human-to-machine networks. These dynamics are evidenced in changes in the relative roles of humans, organizations and machines in those networks, and in the emergence of new interaction patterns and evolutionary trajectories. We can also notice that digital capacities in network settings can become the single most important source of authority, making digital leadership and the private sector experience key enablers of digital collaboration, its process and outcomes. Although digitization provides the public sector with new avenues for public policy-making and implementation, the digital infrastructure depending on its level of maturity and institutionalization - concurrently also limits its choices with the opportunities created by the adopted technology. In other words, the existing digital infrastructure strongly shapes the directionality of collaborative innovation. We also see that the digital dynamics is strongest where organizational context can provide the network leaders the needed resources and legitimacy and where the networks focus on highly standardized services or issues. Thus, we believe that the gained insights from the current exploratory study provide fruitful hypotheses for further studies on collaborative innovation.

\section{Literature}

Alford, J., \& O’Flynn, J. (2012). Rethinking public service delivery. Managing with external providers. London, England: Palgrave Macmillan.

Arthur, W. B. (1989). Competing technologies, increasing returns, and lock-in by historical events. The Economic Journal, 99(394), 116-131.

Baldwin, C. and Von Hippel, E., 2011. Modeling a paradigm shift: From producer innovation to user and open collaborative innovation. Organization Science, 22(6), pp.1399-1417.

Bardach, E. 2008. Developmental Processes: A Conceptual Exploration. In: Borins, S. (ed.) Innovations in Government. Research, Recognition, and Replication. Washington, D.C.: Brookings Institution Press, 113-137.

Baumol WJ (1967) Macroeconomics of unbalanced growth: the anatomy of urban crisis. The American economic review 57(3): 415-426. 
Blomqvist, K. and Levy, J., 2006. Collaboration capability-a focal concept in knowledge creation and collaborative innovation in networks. International Journal of Management Concepts and Philosophy, 2(1), pp.31-48.

Bommert, B. (2010). Collaborative innovation in the public sector. International public management review, 11(1), 15-33.

Bouckaert, G., Peters, B.G. and Verhoest, K., 2010. The coordination of public sector organizations. Hampshire: Palgrave Macmillan.

Brown, A., Fishenden, J., Thompson, M. and Venters, W., 2017. Appraising the impact and role of platform models and Government as a Platform (GaaP) in UK Government public service reform: towards a Platform Assessment Framework (PAF). Government Information Quarterly, 34(2), pp.167-182.

Callon M (1987) Society in the making: The study of technology as a tool for sociological analysis. In: Bijker WE, Hughes TP, and Pinch T (eds) The Social Construction of Technological Systems. Cambridge, MA: MIT Press, 83-110.

Clark, B., Brudney, J. and Jang, S.-G. (2013). Coproduction of Government Services and the New Information Technology: Investigating the Distributional Biases. Public Administration Review, 73(5), pp. 687-701.

Crosby, B. C., P. 'T Hart, and J. Torfing. 2016. "Public Value Creation through Collaborative Innovation." Public Management Review 19 (5): 655-669.

Dosi, G. and Nelson, R.R., 2013. The evolution of technologies: an assessment of the stateof-the-art. Eurasian business review, 3(1), pp.3-46.

Drechsler, W. 2018. Pathfinder: e-Estonia as the $\beta$-version. eJournal of eDemocracy \& Open Government 10(2): 1-22.

Dunleavy, P., Margetts, H., Bastow, S. and Tinkler, J., 2006. New public management is dead-long live digital-era governance. Journal of public administration research and theory, 16(3), 467-494.

Eide, A.W. et al. 2016. Human-Machine Networks: Towards a Typology and Profiling Framework. Paper presented at the 18th International Conference on Human-Computer Interaction International (HCII), Toronto, Canada, 17-22 July. 
Emerson, K., Nabatchi, T., Balogh, S. 2012. An Integrative Framework for Collaborative Governance, Journal of Public Administration Research and Theory, 22(1), 129, https://doi.org/10.1093/jopart/mur011.

Fountain JE (2001) Building the Virtual State: Information Technology and Institutional Change. Washington, D.C.: Brookings Institution Press.

Gil-Garcia, J.R.., Rentería, C. and Luna-Reyes, L.F. (2014) Enacting Collaborative Electronic Government: Empirical Evidence and Lessons for Developing Countries. 47th Hawaii International Conference on System Science. DOI 10.1109/HICSS.2014.284

Gkypali, A., Filiou, D. and Tsekouras, K., 2017. R\&D collaborations: Is diversity enhancing innovation performance?. Technological Forecasting and Social Change, 118, pp.143-152. Hartley, Jean; Sørensen, Eva and Torfing, Jacob (2013). Collaborative innovation: A viable alternative to market-competition and organizational entrepreneurship. Public Administration Review, 73(6), 821-830.

Helfat, C.E. and Raubitschek, R.S., 2018. Dynamic and integrative capabilities for profiting from innovation in digital platform-based ecosystems. Research Policy, 47(8), pp.1391-1399. Huxham, C. and S. Vangen. 2004. 'Doing Things Collaboratively: Realizing the Advantage or Succumbing to Intertia?' Organizational Dynamics, 33, 2, 190-201.

Janssen, M. and Estevez, E. (2013). Lean government and platform-based governanceDoing more with less. Government Information Quarterly, 30, pp. S1-S8.

Kalvet T (2012) Innovation: a factor explaining e-government success in Estonia. Electronic Government: an International Journal, 9(2), 142-157.

Kattel, R., Cepilovs, A., Lember, V., and Tõnurist, P. (2018). Indicators for public sector innovations: Theoretical frameworks and practical applications. Administrative Culture, 19(1), 77-104.

Karo, E. and Kattel, R. (2016). Innovation and the State: Thinking of Government as" Technology Maker" and Implications for Public Administration Research. Administrative Culture, 17 (1), 5 -17. 
Kenney, M. and Zysman, J. (2015). Choosing a future in the platform economy: the implications and consequences of digital platforms. Draft paper presented at Kauffman Foundation New Entrepreneurial Growth Conference, 18-19 June.

Kickert, W., E.H. Klijn and J. Koppenjan (eds). 1997. Managing Complex Networks: Strategies for the Public Sector. London: Sage Publications.

Kitchin, R., Lauriault, T.P. and McArdle, G. 2018. Data and the City. London and New York: Routledge.

Latour, B., 2005. Reassembling the Social, an Introduction to Actor-Network-Theory. Oxford University Press, Oxford

Lember, V., Brandsen, T. and Tõnurist, P. 2019. The Potential Impacts of Digital Technologies on Co-Production and Co-Creation. Public Management Review, DOI:

10.1080/14719037.2019.1619807.

Lember, V., Kattel, R. and Tõnurist, P. 2018. Technological Capacity in the Public Sector: The Case of Estonia. International Review of Administrative Sciences, 84(2), 214-230.

Linders, D. (2012). From e-government to we-government: Defining a typology for citizen coproduction in the age of social media. Government Information Quarterly, 29(4), pp. 446454.

Lowndes, V. and C. Skelcher. 1998. "The Dynamics of Multi-organisational Partnerships: An Analysis of Changing Modes of Governance." Public Administration 76 (2), 313-334.

Mandell M \& T Steelman (2003) Understanding what can be accomplished through interorganizational innovations. The importance of typologies, context and management strategies. Public Management Review, 5:2, 197-224.

Margetts H and Naumann A (2017) Government as a Platform: What can Estonia Show the World? Research Report. Available at:

https://www.politics.ox.ac.uk/publications/government-as-a-platform-what-can-estoniashow-the-world.html (28.04.2017).

Mergel, I. (2016). Social Media in the Public Sector. In: D. Bearfield and M. Dubnick, eds. Encyclopedia of Public Administration and Public Policy. Abingdon: Taylor \& Frances, Vol 3, pp. 3018-3021. 
Mergel, Ines. 2017. Digital Service Teams: Challenges and Recommendations of Government. Available at http://www.businessofgovernment.org/report/digital-serviceteams-challenges-and-recommendations-government.

Mintzberg, H. 1996. Managing government, governing management. Harvard Business Review, 74(3), 75.

Mowery, D.C. (2009). Plus ca change: Industrial R\&D in the "third industrial revolution". Industrial and Corporate Change, 18, 1, 1-50.

Nelson, R. R. and S. G. Winter (1974), 'Neoclassical vs Evolutionary Theories of Economic Growth: Critique and Prospectus', The Economic Journal, 84 (336), 886-905.

Noveck, B.S. (2015). Smart Citizens, Smarter State. The Technologies of Expertise and the Future of Governing. Cambridge, Massachusetts, and London, England: Harvard University Press.

O’Neil, C. (2016). Weapons of Math Destruction. How Big Data Increases Inequality and Threatens Democracy. UK: Allen Lane.

O'Reilly, T. (2017) WTF? What's the Future and Why It's Up to Us. New York: HarperCollins. Propublica. 2016. "Machine Bias", available at https://www.propublica.org/article/machinebias-risk-assessments-in-criminal-sentencing.

Pollitt, C. 2012. New Perspectives on Public Services: Place and Technology. Oxford: Oxford University Press.

Sayes, E., 2014. Actor-Network Theory and methodology: Just what does it mean to say that nonhumans have agency?. Social Studies of Science, 44(1), pp.134-149.

Schmitz Weiss, A. and Domingo, D., 2010. Innovation processes in online newsrooms as actor-networks and communities of practice. New media \& society, 12(7), pp.1156-1171. Shaw-Garlock, G., 2010, Loving machines: Theorizing human and sociable-technology interaction. In International Conference on Human-Robot Personal Relationship (pp. 1-10). Springer, Berlin, Heidelberg.

Sørensen, E., \& Torfing, J. (2011). Enhancing collaborative innovation in the public sector. Administration \& Society, 43(8) 842-868. 
Sørensen, E. and Torfing, J., 2016. 6 Collaborative Innovation in the Public Sector. Enhancing Public Innovation by Transforming Public Governance, p.117.

Stilgoe, J. (2018). Machine learning, social learning and the governance of self-driving cars. Social Studies of Science, 48(1), 25-56.

Teece, D. (2018). Profiting from innovation in the digital economy: Enabling technologies, standards, and licensing models in the wireless world. Research Policy, 47, 1367-1387. Tsvetkova, M., Yasseri, T., Meyer, E. T., Pickering, J. B., Engen, V., Walland, P., ... \& Bravos, G. (2017). Understanding human-machine networks: a cross-disciplinary survey. ACM Computing Surveys (CSUR), 50(1), 12.

Tõnurist, P.; Kattel, R.; Lember, V. 2017. Innovation labs in the public sector: what they are and what they do? Public Management Review, 19(10), 1455-1479.

Verhoest, K. et al. (2017). Theoretical and analytical framework. Case selection and approach. WP1 Report: Public Sector Innovation through Collaboration (PSI-CO).

Zuboff, S., 2015. Big other: surveillance capitalism and the prospects of an information civilization. Journal of Information Technology, 30(1), pp.75-89. 